\title{
The Effects of Cooperative Learning Strategies on Vocabulary Skills of 4th Grade Students
}

\author{
Didem Bilen $^{1}$, Zekiye Müge Tavil ${ }^{2}$ \\ ${ }^{1}$ Ankara Maya Schools, Ankara, Turkey \\ ${ }^{2}$ English Language Teaching Department, Gazi University, Ankara, Turkey \\ Correspondence: Zekiye Müge Tavil, English Language Teaching Department, Gazi University, Ankara, Turkey
}

Received: July 30, 2015 Accepted: August 11, $2015 \quad$ Online Published: August 31, 2015

doi:10.11114/jets.v3i6.1062 URL: http://dx.doi.org/10.11114/jets.v3i6.1062

\begin{abstract}
This study was carried out to investigate the effects of cooperative learning strategies on the vocabulary skills of $4^{\text {th }}$ grade students. The study was also designed to ascertain the attitudes of the students in the experimental group towards cooperative learning. Out of $964^{\text {th }}$ grade students enrolled in the private school where the study took place, 48 participated in this study. In order to find out whether there was a significant difference between the vocabulary scores for the experimental group and the control group, a pre-test and a post-test were administered to both groups. The data gathered from the students' lesson diaries was used to find out what they thought about cooperative learning strategies. In addition, the teacher of the experimental group was interviewed to verify the results obtained from the lesson diaries. The data gathered from the pre and post tests, lesson diaries and the teacher interview was analyzed both quantitatively and qualitatively. The data obtained from the pre and post tests was analyzed with the Mann-Whitney $U$ test and the Wilcoxon Signed-Ranks Test, while the data gathered from the lesson diaries and the teacher interview was subjected to content analysis.

The findings revealed that there was a significant difference between the results of the experimental group and the control group on the post-tests. The experimental group had a higher score on the post-test than the control group. The analysis of the lesson diaries also indicated that the students' positive attitudes towards cooperative learning strategies increased progressively during the study. Lastly, the analysis of the teacher interview confirmed that the students' positive attitudes towards cooperative learning strategies during the study were genuine.
\end{abstract}

Keywords: strategy, structure, learner-centred learning

\section{Introduction}

Teachers in state schools have recently started to become aware of the importance of interaction in language learning in Turkey. The reason for this increased awareness was the development of the new curriculum by the Turkish Ministry of Education. According to the Council of Europe (as cited in the national curriculum by the Turkish Ministry of Education, 2001), the classroom interaction is emphasised in order to help the learners become a language user, rather than a learner of the language. Teachers in private schools have understood the significance of classroom interaction and taken it into consideration while designing their syllabi, since the course books from which these syllabi are derived use the framework of communicative approaches and introduce many activities based on student-student interaction. Traditional methods that teachers implement in the classroom in previous years did not help them achieve the aims found in the curriculum. They sought new methods and approaches based on communicative activities and student-student interaction, ones they had not used before in the classroom.

Teachers can benefit from social learning theories to understand how learners actually learn through social interaction (learning from each other) while they are seeking for new methods. Vygotsky (1962), a Russian teacher and psychologist, stated that we learn by interacting and communicating with others. Vygotsky (1962) also studied how social environments influence the learning process of the students. He pointed out that learning appears through the interactions with their peers, teachers, and other experts. Regarding Vygotsky's views about social interaction, teachers can create a learning environment that maximizes the learner's ability to interact with each other through discussion, collaboration, and feedback. "Every function in the child's cultural development appears twice: first, on the social level, and later, on the individual level; first, between people (interpsychological) and then inside the child 
(intrapsychological). This applies equally to voluntary attention, to logical memory, and to the formation of concepts. All the higher functions originate as actual relationships between individuals"(Vygotsky, 1978). This means that a child first learns new information through interaction with others on a social level, and then s/he masters the new knowledge or skill on an individual level. Vygotsky's social learning views have inspired both linguists and educationalists in terms of how they view the effect of interaction on the learning process. Recently, it has been supported by the educationalists that teachers should create an effective teaching environment, which includes interaction with the help of a learner-centred approach, not a teacher-centred one (Nunan, 1992; Van Lier, 1996; Richards \& Rodgers, 2001; Swain, 2001; Swain \& Lapkin, 2002). The capability of the learners to use the language fluently increases gradually if the teacher introduces an effective teaching environment to the learners. Nunan (1992) indicates that interaction with other learners in a learner-centred classroom helps the learners to promote their language skills. According to Van Lier (1996), interaction is more than a source of comprehensible input. Interaction also offers learners many opportunities to use the target language that is the output (cited in Swain, 2001). Some of the studies conducted by Swain (2001) and Lapkin (2002) found out that collaborative interactions offer the teachers and the students to work together, produce intellectual activities, and create the appropriate conditions for language learning. As they stated above, the teacher should use interaction with appropriate activities in a learning environment so the students can master the language effectively.

As the communicative approach started to gain popularity in language teaching circles, a student-centred approach in which interaction plays a big role has started to inspire teachers. Unlike traditional methods, this new approach emphasizes the importance and necessity of communication rather than grammar. Whereas learning was teacher-centred in traditional methods, in classrooms where the communicative approach was implemented, student-centred learning was given priority. Following the communicative approach, new approaches based on it started to appear in teaching circles. Cooperative learning is one of these approaches; it is also based on interaction between students in a learner-centred classroom environment. Kessler (1992) emphasizes that cooperative learning is a kind of approach that focuses on structured group works in which student-student interaction plays a big role. The application of cooperative learning to classroom teaching started in the 1970s when Israel and the United States began to study cooperative learning models for the classroom. We also can define cooperative language learning as an extension of communicative language teaching (CLT). Like CLT, it is a learner-centred approach and emphasizes learner interaction. CLL provides this interaction among learners in the classroom and helps students acquire the target language naturally. Richards \& Rodgers (2001) state that if the learners work cooperatively in the classroom, this cooperation creates a positive atmosphere in which the learner's stress is reduced and motivation is increased. It also introduces a cooperative learning environment instead of a competitive environment. Richards \& Rodgers (2001) point out that traditional methods in language teaching were not learner-centred and that these methods created a competitive classroom atmosphere for the learners.

With the rise of cooperative language learning, teachers have started to apply cooperative learning strategies while teaching the four main skills, grammar, and vocabulary in their classroom. Cooperative learning introduces many cooperative learning strategies developed by key researchers in this area (Kagan, 1985; Sharon, 1990; Slavin, 1995; Johnson \& Johnson, 1999). "Cooperative learning strategies refer to a variety of teaching methods in which students work in small groups to help one another learn academic content. In cooperative classrooms, students are expected to help each other, to discuss issues and argue with each other, to assess each other's understanding of the topic, and fill in gaps in each other's learning" (Slavin, 1995). In this study, Kagan structures will be used as cooperative learning strategies to teach vocabulary to $4^{\text {th }}$ grade students. The researcher chose Kagan structures because of the age of the students. Since the study will be conducted with young learners, cooperative learning strategies should be suitable for this age group. Kagan (2011) refers to the structures as step-by-step, simple activities. According to Kagan, the instructions of the structures are short, clear and easy to understand for both the teacher and the students. Kagan (2011) also states that Kagan structures can be used during any stage of the learning process. "RallyRobin can be used as a set for any lesson (name things you already know about the topic; name things you would like to learn about the topic), for practice (take turns inserting colorful adjectives into a sentence frame), or for closure (name things you have learned)" (Kagan, 2011). Kagan (2011) also points out, "The structures are flexible, powerful tools which make teaching easier and learning more engaging and successful across the range of grades and academic content areas". Kagan structures ensure equal participation of all group members. Whereas the roles of the group members differentiate in other cooperative learning strategies, group members' responsibilities are similar in Kagan structures. As previously stated in chapter II, one of the Kagan structures called 'Showdown', which will be used in this study, gives leadership responsibility to each group member in turn. Kagan (2011) notes that, "Using the Round Table structure in place there is no need for the roles or group processing - the structure equalizes the participation; everyone participates about equally. Using Kagan Structures radically reduces the need to assign roles and process group interaction”. The instructions for the structures resemble the instructions of a game. They are fun, especially for young children. Kagan (2003) also talks about their appeal for young learners: "The Kagan Structures make teaching and learning more fun, more engaging, and 
more successful". Kagan structures positively affect social skills in addition to their use as a way to improve academic performance. As Davoudi \& Mahinpo (2012) indicate, "Kagan structures introduce a long list of social skills, including listening, taking turns, speaking, conflict resolution skills, leadership skills, and teamwork skills. Students coming from cooperative learning classrooms are more polite and considerate of others. They can make team learning in language learning and they say their ideas and attitudes to second language". A learner-centred strategy is a major part of all Kagan structures. Teachers provide the instructions. Then they let students work in groups. During the activities, the students do all the talking and all the work. They become more engaged in the learning and more eager to learn. There have been many studies on the effect of cooperative learning on language teaching. Liang (2002) studied the effects of cooperative learning on EFL junior high school learners' language learning, motivation toward learning English as a foreign language, and the high- and low-achievers' academic achievements in a heterogeneous language proficiency group. The major findings of this study suggested that cooperative learning significantly enhanced the junior high school learners' oral communicative competence and their motivation toward learning English. Bayat (2004) investigated the effect of cooperative learning on reading skills and student attitudes. She states that cooperative language learning has a positive and motivational effect on learners' language learning process. Ghorbani (2012) investigated whether cooperative language learning positively affected the teaching of grammar. The findings showed that the interaction which the learners had during the grammar sessions affected their learning environment positively. Zarei \& Gilani (2013) examined the effects of selected collaborative techniques on second language (L2) vocabulary comprehension and production. The researcher found out that word webbing was the most effective technique for both vocabulary comprehension and production. The findings of the present study may have theoretical as well as practical implications. Tekeli (2013) investigated the effects of cooperative learning in developing students' writing performance and their ability to produce grammatically coherent work. The results showed that cooperative learning was effective on developing students' general writing performance and grammar skills.

Vocabulary teaching is one of the most important parts of language teaching because the words in a sentence play an important role in conveying the meaning. In a classroom in which traditional methods are implemented, the learners have difficulties in learning new vocabulary words. The underlying reason for this problem is the fact that most teaching techniques, such as using dictionaries and getting definitions lead learners to memorize words. Scrivener (1998) states that acquiring words is a difficult process since our memory may not allow us to acquire all necessary words. Even if we acquire the words, we may not be able to use them meaningfully. Using dictionaries, reading definitions, and listening to examples from teachers are not effective ways to deal with this problem. As teachers, we should find systematic ways of helping children with vocabulary. Akar (2010) reminds us, "Long-term memory (LTM) can accommodate an unlimited amount of information. However, we need to work hard to store information in LTM. Repetition may not be adequate; we may need to apply through processing and systematic organisation". For years, teachers have been trying to find out how to get vocabulary words to stay firmly ensconced in long-term memory. Cooperative learning strategies presents many activities to be able to teach vocabulary. Kagan (1985) developed many structures. The word 'structure' means systematic instructional strategies. He designed these structures to increase student engagement and cooperation. They can be effective in vocabulary teaching too since the activities may help the learners to plant the words in their long-term memory and use them appropriately. Since there are some gaps in the study of the effects of cooperative language learning on vocabulary teaching, the researcher can extend the scope of the study by looking at different contexts.

In order to fill this gap in this area, the researcher has the following research questions:

1. "Is there a significant difference between vocabulary skills and retention of the learners who practice with cooperative learning strategies (Kagan Structures) and the achievement on vocabulary learning of the learners versus those who practice traditional method activities?"

2. "What are the learners' attitudes towards cooperative learning strategies?"

\section{Method}

The researcher divided 48 students into two groups (the experimental group and the control group) to carry out the study. Both groups had 24 students. The researcher administered a pre-test before the study. One of the teachers implemented cooperative learning strategies (Kagan Structures) to teach the selected vocabulary items in the experimental group, while another teacher implemented the traditional method to teach these vocabulary items in the control group. The study lasted five weeks. After the study, the researcher administered a post-test to investigate the effects of cooperative learning strategies on vocabulary teaching comparing the results of these two groups. The researcher prepared a completely different post-test to provide the validity of the test. There was a possibility that the learners could remember some words from the pre-test while taking the post-test. Therefore, the researcher uses the same vocabulary items with different types of question types in the post-test. The vocabulary items in the pre-test and post-test are the same. 


\subsection{Participants}

The researcher chose to select participants for the study from the private school where she works; she therefore had the advantage of observing the experimental group at any time. The study includes 48 participants, all of whom are primary school students in two different classes in that private school. They are $4^{\text {th }}$ grade students, who are at A1 level according to the Common European Framework. The participants have English classes for 15 hours in a week. They are taught core language skills (reading and listening) for 13 hours and productive skills (speaking and writing) for 2 hours. They have never been exposed to any cooperative learning instructions before. The experimental group included 13 female and 11 male students.

\subsection{Instruments}

Three different instruments were used to collect data for this study. Because an experimental research design was used for this study, the participants were divided into two groups: the experimental group and the control group. Quantitative data was collected from the pre-test and the post-tests and qualitative data was collected from the lesson diaries and the interview with the teacher who implemented Kagan structures in the classroom with the experimental group.

The pre-test was piloted with other two groups of $4^{\text {th }}$ grade students for reliability. It consisted of the new vocabulary items, which will were taught by the teacher during the study. The pre-test consisted of 30 vocabulary items, and it was pieced together from different kinds of vocabulary tests. It consisted of four main parts. Two of the parts with 15 items were formed to test vocabulary recognition and the other two parts with 15 items were formed to test vocabulary production. The vocabulary items, which were used in the pre-test, were selected from the reading and listening texts in the participants' course books. The same reading and listening texts used for the experimental group were also used for the control group. After the study was completed, the post-test was administrated to both the experimental group and the control group to be able to compare the two groups in terms of how well they learned vocabulary. The post-test covered the same vocabulary items, which were used in the pre-test with different kinds of activities. The researcher did not use the same pre-test as the post-test in case the participants remembered the questions. The researcher administered a different test as the post-test to increase the reliability of the study.

The researchers used the lesson diaries to learn about the attitudes of the participants towards the cooperative groups. The lesson diaries were only used by the participants in the experimental group. The participants stated why they liked the cooperative activities or why they did not like these groups in the lesson diaries. The researcher learned the participants' views on vocabulary lessons after each study. The researcher aimed to find out whether vocabulary teaching with different techniques got the attention of the participants or not.

Another tool, which the researchers used for this study was interviews. The researcher interviewed the teacher who taught the experimental group to confirm the views the participants had about the lessons. The researcher asked about the learners' attitudes towards Kagan structures. The researcher also confirmed what the learners said about the cooperative learning activities by interviewing the teacher.

\subsection{Procedure}

At the beginning of the study, the researcher obtained the related documents for the literature review through university libraries and the internet using the key words "Cooperative Learning", "Kagan structures", and "vocabulary teaching". After completing the literature review, the researcher got the necessary permission from the school administration and selected the experimental group and the control group from $4^{\text {th }}$ grade students without discriminating based on their gender and social-educational background. The experiment was conducted at a private school, at the beginning of the second term of the 2014-2015 academic year. Thirty target vocabulary items, which to be taught during the experiment, were selected from the reading and listening texts in the learners' course book. Those vocabulary items were grouped according to the curriculum. In the curriculum, those words were key words for the unit, which would be presented during the study. The researcher prepared a vocabulary test covering these vocabulary items to be sure that the participants did not know the words beforehand. Before she administered the pre-test to the experimental and the control group, the researcher piloted the test with forty-eight different $4^{\text {th }}$ graders at the same primary school to ensure the test's validity. According to the test was valid. The vocabulary items were tested in a contextual way through the pre-test and post-test. Both the recognition and the production aspects of vocabulary teaching were taken into consideration.

Lesson diaries were written by the experimental group after each session of vocabulary teaching. The samples wrote about their feelings, comments about the lesson, and attitudes towards group work. 112 lesson diaries were written by the experimental group students during the study. The lesson diary was designed by the researcher and carried out by the teacher of the experimental group. After the lesson diaries were analyzed, the researcher interviewed the teacher of the experimental group to confirm what the students wrote in the lesson diaries. The researcher also benefited from the 
teacher's observation during the study. The researcher used the following to collect the data: a pre-test and post-test, lesson diaries and a teacher interview.

\subsection{Data Analysis}

The data, which was gathered through three different instruments during the study, was analyzed both quantitatively and qualitatively. The quantitative data was collected by means of pre and post-tests in order to find out whether there was a significant difference between the pre and post-tests in either the control or the experimental group. The researcher used some programmes such as Microsoft Excel and SPSS to analyze the data quantitatively. The data was collected qualitatively through diaries and interviews with the teacher and analyzed to discover the perceptions of the participants during the implementation in the class in which Kagan Structures were used.

Before analyzing the pre-test and post-test data, all of the parts from both tests were assessed by two different teachers. The correct answers in the pre-test were counted. The vocabulary pre-test involved 301 -point questions. The maximum score on the pre-test was 30 points. The post-test was graded in the same way. After the assessment part, the researcher calculated the points and prepared a table using Microsoft Excel. The researcher then made the necessary calculations. The data gathered through the pre-test and the post-test was analyzed by a statistician to find out whether there was a significant difference between the pre and post-tests from both control and experimental groups. The analysis of the tests was completed using SPSS.

The diaries, the participants filled out during the study, were subjected to content analysis. The diaries were read by the researcher. The researcher got the key points related to the study and put the items in the diaries into different categories. The researcher prepared a table for the diary results using Microsoft Excel. Then the researcher entered the data to prepare graphics for the comments obtained from the lesson diaries.

The interview with the teacher was also analyzed qualitatively. It was transcribed and subjected to content analysis. After that, the analysis of the diaries and the analysis of the interview were compared with one another to see if there were similarities between the lesson diaries of the students and the opinions of the teacher of the experimental group.

\section{Results}

\subsection{The Analysis of the Pre-test and the Post-test}

\subsubsection{The Normal Distribution Analysis of Data}

Before starting a statistical analysis for a study, the data needs to be checked in order to determine if it has a normal distribution or not. If the data is normally distributed, the analysis is done using parametric tests. If the data is not normally distributed, the analysis is done using non-parametric tests.

Since it is $\mathrm{n} \leq 50$ in data set, the Shapiro-Wilk test is used for normality distribution. According to this test, if it is $\mathrm{p} \geq 0.05$, the researchers accept that distribution is normal (Field, 2011, Büyüköztürk, 2012). The tables and histograms related to this test are shown below:

Table 1.The Normal Distrubition Analysis of the Data

\begin{tabular}{lccc}
\hline Values & Statistic & sd & $\mathrm{p}$ \\
\hline Control PRE &, 961 & 24 &, 461 \\
Control POST &, 840 & 24 &, 001 \\
Experimental PRE &, 948 & 24 &, 249 \\
Experimental POST &, 932 & 24 &, 106 \\
\hline
\end{tabular}

As shown in the table 1, among four different variables, which have been processed, the $\mathrm{p}$ value of three variables is over 0.05 , while only one of them is less than 0.05 . Because of these results, non-parametric tests were used to complete the analysis of this study and answer the research questions. The scatter plots related to the normality are given as follows: 

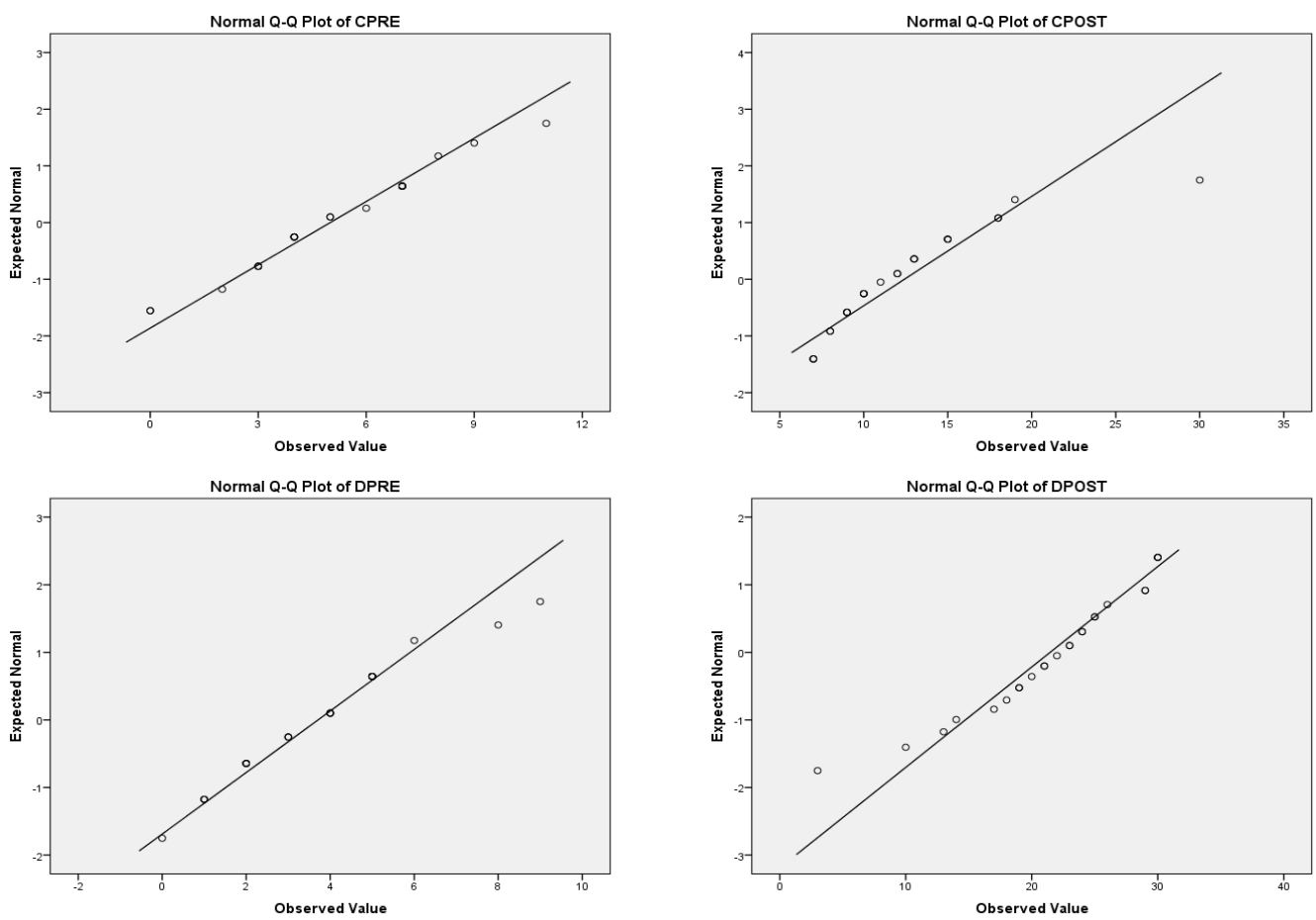

Figure 1. The Scatter Plots of the Normality

\subsubsection{Mann-Whitney U Analysis of the Data}

The Mann-Whitney U test, which is one of the non-parametric groups, is used to find out whether there is a statistically significant difference between the pre-tests and the post-tests, which have been administered to two independent groups.

The results of pre-tests analysis are as follows:

Table 2. The Results of Mann-whitney U Test for The Pre-tests

\begin{tabular}{cccccc}
\hline Group & $\mathrm{n}$ & Mean Rank & Sum of Ranks & $\mathrm{U}$ & $\mathrm{P}$ \\
Control PRE & 24 & 27,90 & 669,50 & & \\
Experimental PRE & 24 & 21,10 & 506,50 & 206,500 & 0.09 \\
\hline
\end{tabular}

Table 2 states whether or not there is a difference between the pre-tests of the control group and the experimental group.The Mann-Whitney $U$ test was used in order to find out whether there is a statistically significant difference between the pre-tests of the control group and the experimental group. As seen in the table, the mean rank of the experimental group is 21.10 while the mean rank of the control group is 27.90 . The sum of the ranks of the experimental group appears to be 506.50 while the sum for the control group is 669.50 . According to the results of the test, there was not a statistically significant difference between two groups, which included 48 students in total $(U=206,500 ; p>0.05)$.

When the mean ranks of the two different groups were analyzed, it was clearly understood that the students in the control group had much higher than the students in the experimental group. It also means that the students in the control group knew more vocabulary items before the study was carried out.

Table 3. The Results of the Mann-whitney U Test for The Post-tests

\begin{tabular}{cccccc}
\hline Group & $\mathrm{n}$ & Mean Rank & Sum of Ranks & $\mathrm{U}$ & $\mathrm{P}$ \\
Control POST & 24 & 15,77 & 378,50 & & \\
Experimental POST & 24 & 33,23 & 797,50 & 78,500 & 0.00 \\
\hline
\end{tabular}

This table states whether or not there is a difference between the pre-tests of the control group and the experimental group.

The Mann-Whitney U test was used in order to find out whether there is a statistically significant difference between the post-tests of the control group and the experimental group. According to the results of the test, there was a statistically significant difference between the two groups, which included 48 students in total $(U=78,500 ; p<0.05)$.

When the mean ranks of two different groups were analyzed, it was clearly understood that the students in the experimental group scored significantly higher on the post-test than the students in the control group. It means that the students in the experimental group knew more vocabulary items after the study was carried out. According to the results of the post-test, it can be stated with certainty the vocabulary knowledge of the experimental group improved much more than the vocabulary knowledge of the control group. 
In the next stage of the analysis, the Wilcoxon Signed-Ranks test for paired measurements was used to find out whether or not cooperative learning strategies had a positive effect on the subjects. If the data was normally distributed, a paired-samples t-test would be used. Because the data was not normally distributed, the non-parametric version of the same test was used.

\subsubsection{Wilcoxon Signed-ranks Test}

The Wilcoxon Signed-Ranks test was used to find out whether there is a statistically significant difference between the pre-test and the post-tests, which were administrated to the experimental group.

Table 4. Analysis of Wilcoxon Signed-ranks Test between the Pre-tests and the Post Tests of the Experimental Group

\begin{tabular}{ccccccc}
\hline PRE-POST TEST & $\mathrm{n}$ & Mean Rank & Sum of Ranks & $\mathrm{z}$ & $\mathrm{P}$ \\
Negative Ranks & 0 & 0,00 & 0,00 & & \\
Positive Ranks & 23 & 12,00 & 276,00 & $4.202^{*}$ & 0.00 \\
Equal & 1 & & & & \\
\hline
\end{tabular}

*Based on negative ranks

The Wilcoxon Signed-Ranks test was used to test whether there is a statistically significant difference between the tests, which were administrated to the experimental group before and after cooperative learning strategies were implemented. The results of Wilcoxon Signed-Ranks test were given in Table 4.4.

As seen in table 4.4. the negative ranks gained from the pre-post test of experimental group are 0 , while the positive ranks are 23, and 1 equal. In addition, the mean rank of the negative ranks is 0,00 and 12,00 for positive ranks. There appears to be 0,00 sum ranks for negative and 276,00 for positive ranks. The results of the analysis have shown that there is a significant difference between the vocabulary knowledge of the students in the experimental group before cooperative learning strategies were implemented and their vocabulary knowledge after the treatment, $\mathrm{z}=4.202 ; \mathrm{p}<0.05$. Regarding the mean ranks and sums of difference points, this difference clearly comes out in favour of the post-test.

According to the results, the students who learn vocabulary items using cooperative learning strategies score significantly higher on the post-test than the students who learn vocabulary items through traditional methods.

\subsection{The Analysis of the Lesson Diaries}

The researcher analyzed the lesson diaries qualitatively. There were 112 diary sheet in total, which were filled by the students in the experimental group. The researcher identified the most frequent ones among the comments in the lesson diaries and divided them into two main categories as positive and negative. Both positive comments and negative comments were categorized in accordance with the three sub-scales as English, Group work and Activities. The researcher identified 162 positive comments. In English section, there are 4 different comments. In Group work section, there are 7 different comments. In Activities section, there are 7 different comments. The most frequently encountered positive comments are shown in table 4.5.

Table 5. Most Frequent Positive Comments from the Experimental Group

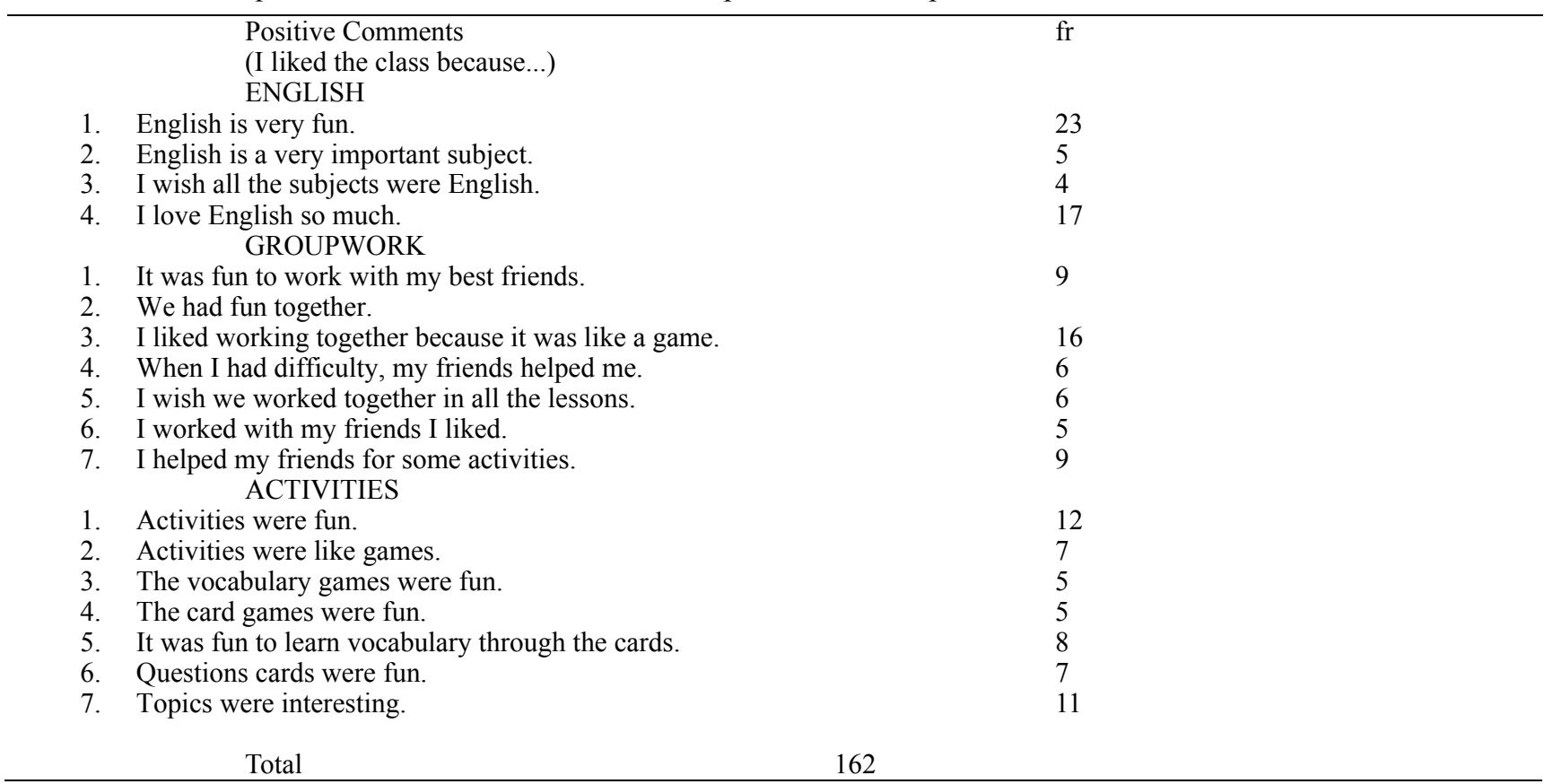


The researcher identified 67 negative comments. In English section, there are 2 different comments. In Group work section, there are 4 different comments. In Activities section, there are 2 different comments. The most frequently encountered negative comments are shown in table 4.6.

Table 6. Most Frequent Negative Comments from the Experimental Group

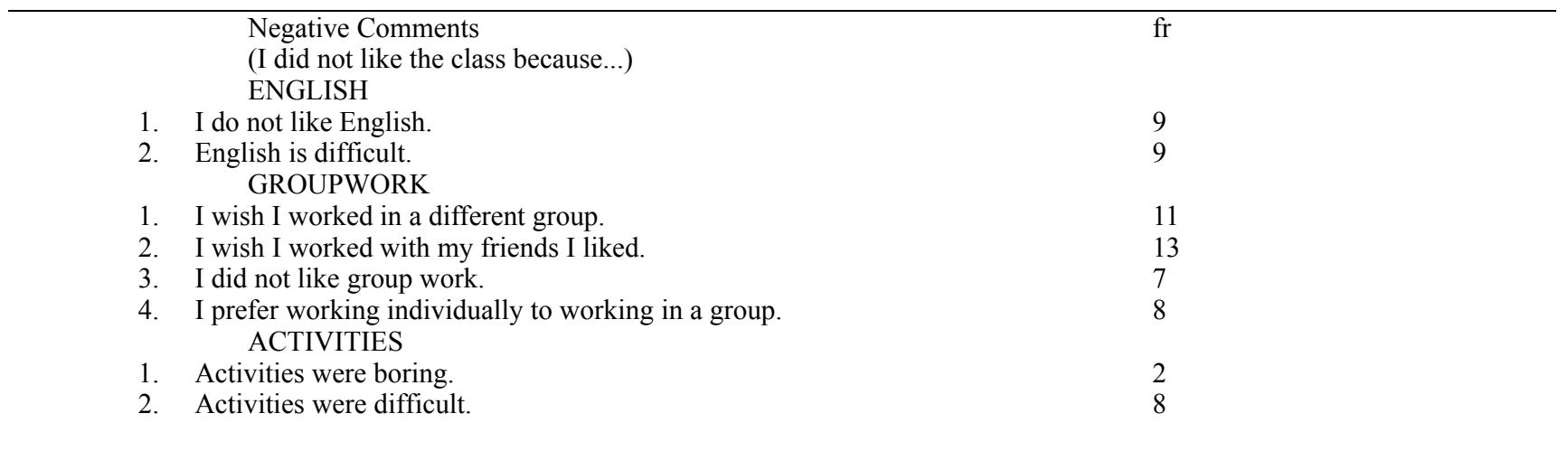

Total 67

The researcher divided the data collection into three distinct periods: the first week, the middle weeks, and the last week. The comments of the second, the third, and the fourth weeks were categorized under middle weeks. The most frequent comments gathered from these periods were compared. The results of the analysis were given as follows:

When we look at the English section, there are four different positive comments. It can be easily understood that positive comments, which were done on the English section increased during the weeks. The range of the comments in the English section was given in Figure 4.2. In the first week, five of the students stated that English is very fun. In the middle weeks, seven of the students stated the first comment. In the last week, eleven of the students repeated the first comment. The second comment was not cited in the first week but cited twice in the middle weeks and three times in the last week. None of the students cited the third comment in the first week. The third comment was stated once in the middle weeks and three times in the last week. Lastly, two of the students stated the fourth comment in the first week. It was cited five times in the middle weeks and ten times in the last week.

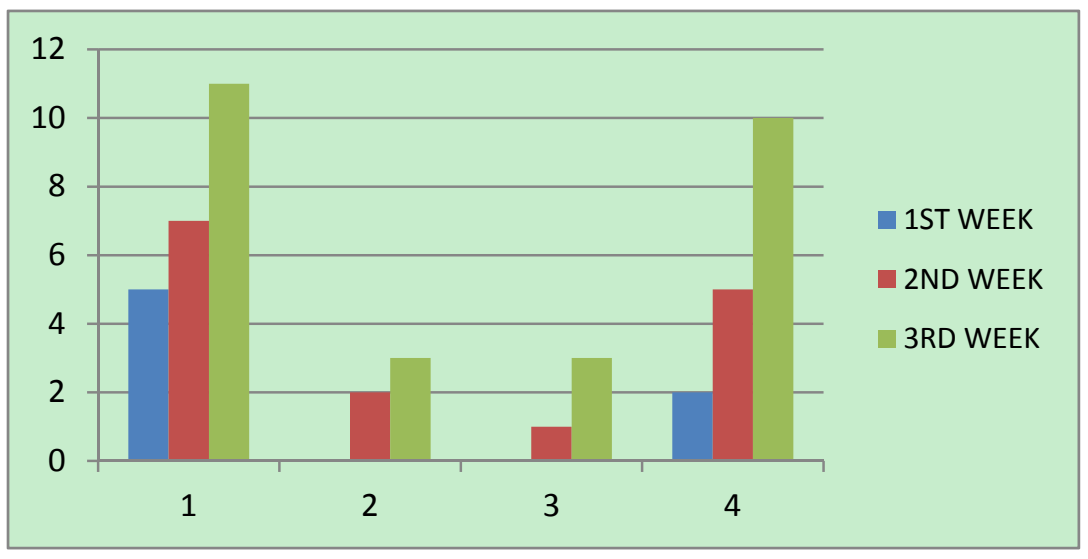

Figure 2. The range of positive comments on the English section during the study

When the Group work section was analyzed, there were seven different comments. The range of the comments in the Group work section was given in Figure 4.3. Regarding the results in Figure 4.3, it was noted that the frequencies of positive comments concerning the Group work dimension increased as the study went on. In the first week, one of the students stated that it was fun to work with their best friends. Three of the students stated the first comment in the middle weeks and five of them cited a similar comment in the last week. Two of the students cited the second comment twice in the first week. In the middle weeks, this comment was cited four times, and it was noted ten times in the last week. The third comment was stated once in the first week, twice in the middle weeks and three times in the last week. One of the students stated that when she had difficulty, her friends helped her. This comment was cited three times in middle weeks and twice in the last week. The fifth comment was not stated in the first week but was cited twice in the middle weeks and three times in the last week. Two of the students reflected on their experience, saying that they wished they had worked with the friends they liked in the first week. This comment was noted four times in the middle weeks and three times in the last week. Two of the students stated that they liked helping their friends during the activity in the first week. This comment was noted three times in the middle weeks and twice in the last week. 


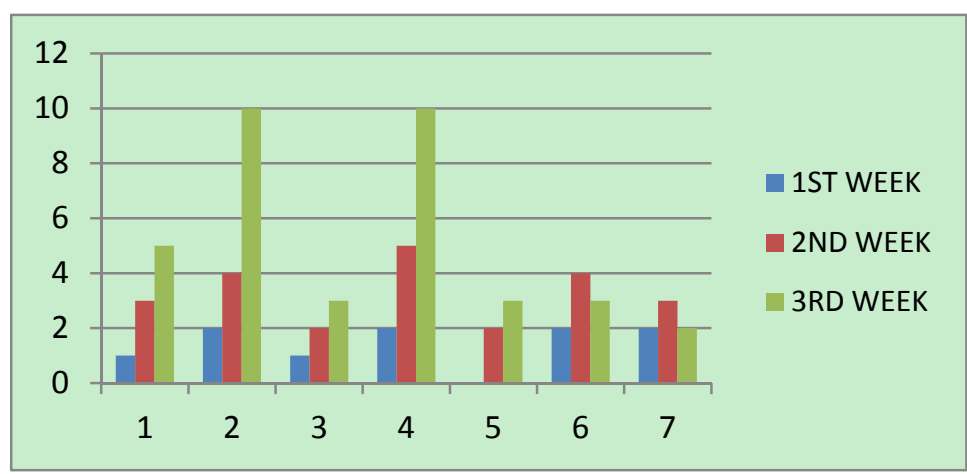

Figure 3. The range of positive comments regarding the Group work section during the study

In terms of the Activities section, there are seven different comments in total. The range of the comments in Activities section was given in Figure 4.4. When we look at the results of this section, it can be seen that the frequencies of positive comments in the middle weeks and in the last week are higher than in the first week. In the first week, four of the students stated that activities were fun and they like them. The first comment was stated three times in the middle weeks and five times in the last week. The second comment was cited once in the first week, three times in the middle weeks, and three times in the last week. None of the students stated the third comment in the first week. Three of the students stated the third comment in the middle weeks. This comment was cited twice in the last week. The fourth comment was not stated by any of the students in the first week, but it was stated twice in the middle weeks and three times in the last week. The fifth comment was not stated in the first week but it was stated three times in the middle weeks and five times in the last week. None of the students cited the sixth comments in the first week but it was cited four times in the middle weeks and three times in the last week. Five of the students reflected that topics were interesting in the first week. This comment was cited three times in the middle weeks and three times in the last week.

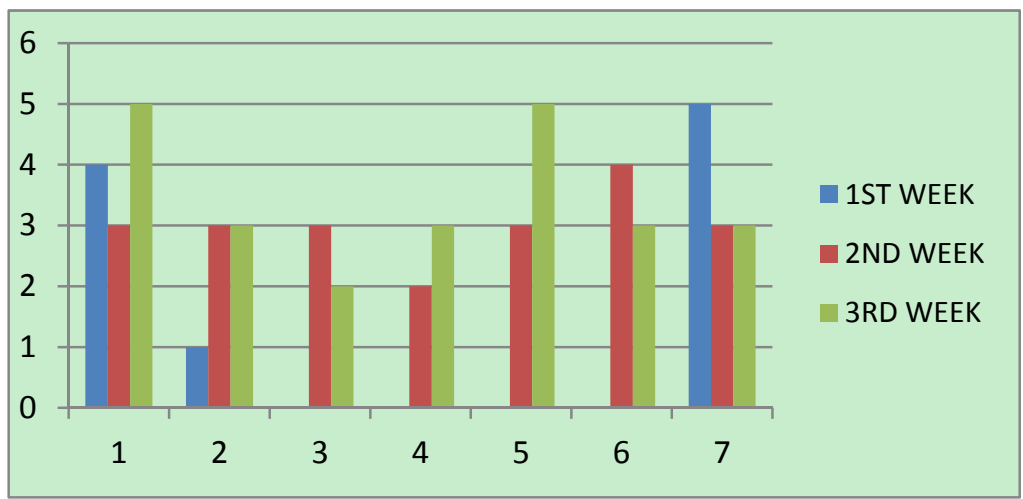

Figure 4. The range of positive comments on regarding the Activities section during the study

According to the results shown in figure 4.5, twenty-six positive comments were stated by the students in the first week. In the middle weeks, fifty-seven students cited positive comments in their lesson diaries. In the last weeks of the study, seventy-nine students stated positive comments in their lesson diaries. Regarding the results, it can be seen that the number of positive comments increased as the study progressed. These results reveal that the students' attitudes towards English, group work, and the activities changed in a positive way.

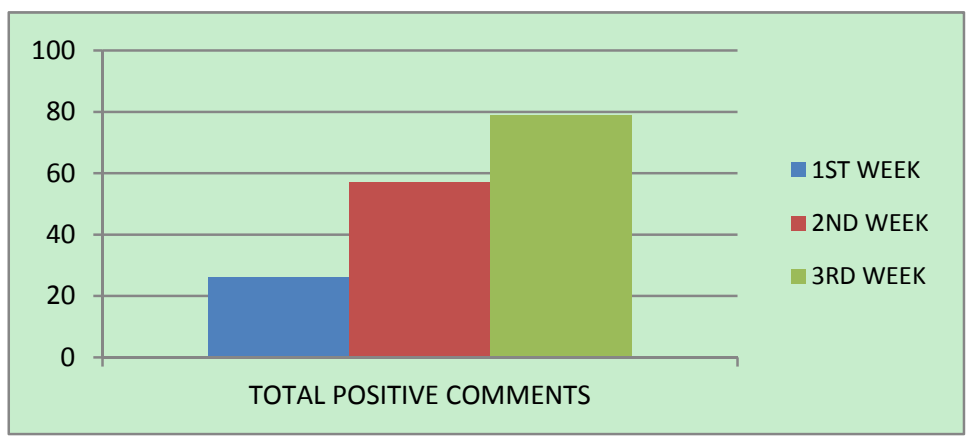

Figure 5. The range of total positive comments during the study

As the second stage of the diary analysis, the negative comments were subjected to content analysis and the frequency 
of the comments was entered into the computer to prepare the graphics. The results for the negative comments are found below:

In terms of the English section, there are two different comments in total. In the first week of the study, three of the students reported that they did not like English. The first comment was cited three times during the middle weeks and three times in the last week. In the first week, four of the students stated that English is a difficult subject. During the middle weeks, three of the students cited the same comment in their diaries. In the last week, two of the students reported that English is difficult. According to the results, the frequency of the second comment decreased during the study. It can be seen that the number of the students who had difficulties during English lessons decreased as the study went on and that group work activities can help change attitudes.

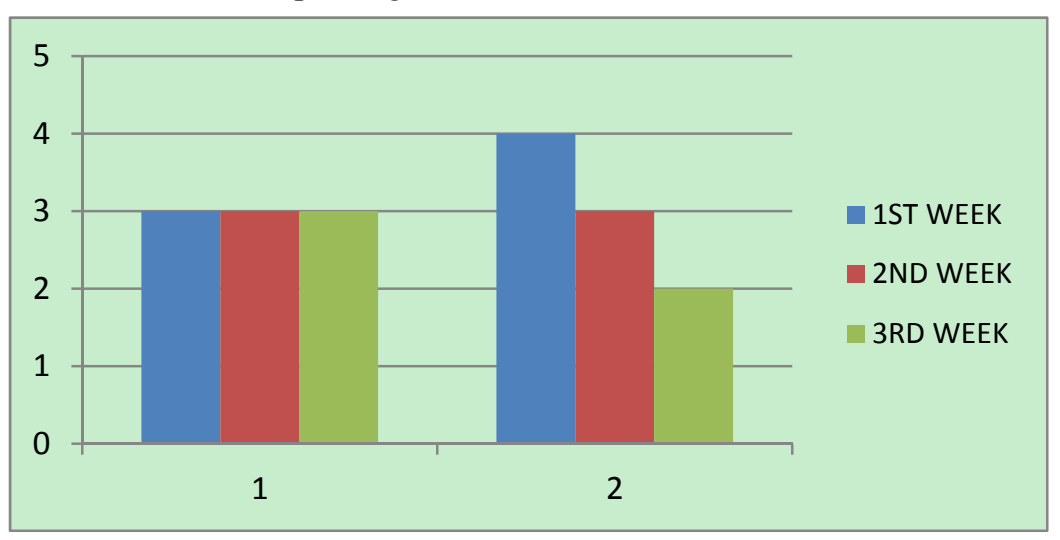

Figure 6. The range of negative comments concerning the English section during the study

Regarding the group work section, there are four different comments. In the first week of the treatment, five of the students reported that they wanted to work in a different group. During the middle weeks, four of the students stated the same comment in their diaries. In the last week, the first comment was cited twice. According to the results, it can be stated that the students wanted to work in another group. Since the teacher changed the groups in each session, the frequency of this comment decreased during the study. In longer treatment periods, all the students would have a chance to work the group of their choosing. In the first week, four of the students reflected on the fact that they did not like the lesson because they did not work with their

friends. The second comment was stated four times during the middle weeks and five times in the last week. According to the results, there was no decline in the frequency of the second comment. Three of the students stated that they did not like the group work in the first weeks of the study. This comment was stated twice in the middle weeks and twice in the last week. The fourth comment was stated by four students in the first of the week. They reported that they preferred working individually to group work. This comment was stated three times in the middle weeks and twice in the last week. Regarding the results, the frequencies of the three comments (except for the second comment) decreased during the weeks. There was an increase in the frequency of the second comment.

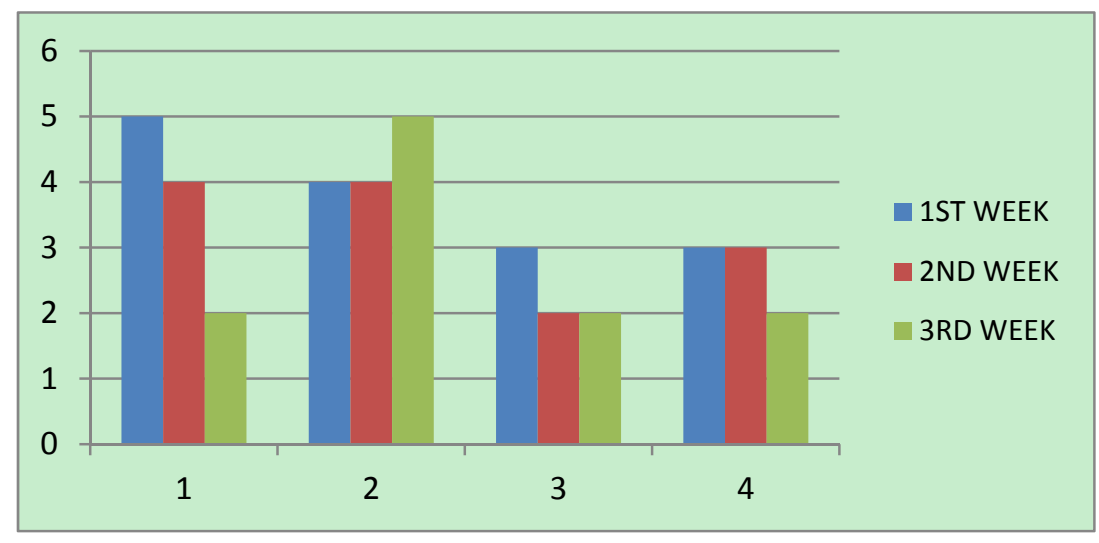

Figure 7. The range of negative comments concerning the Group work section during the study

In terms of the Activities section, there are two different comments in total. In the first weeks of the treatment, two of the students reported that the activities were boring. During the middle weeks and the last week, none of the students stated the first comment in their diaries. Three of the students stated that activities were difficult in the first week of the 
study. The second comment was reported three times during the middle weeks and twice in the last weeks. According to the results, it can be seen that there was a decrease in the frequency of the second comment.

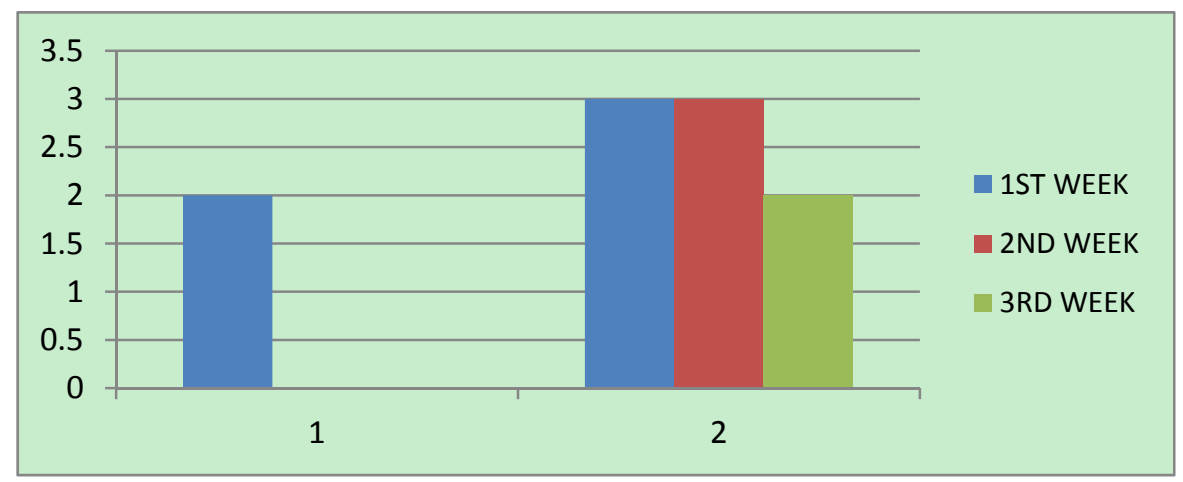

Figure 8. The range of negative comments concerning the Activities section during the study

According to the results shown in figure 4.9, twenty-seven negative comments were stated by the students in the first week. In the middle weeks, twenty-two students cited negative comments in their lesson diaries. In the last weeks of the study, eighteen students stated negative comments in their lesson diaries. Regarding the results, it can be reported that the frequencies of total negative comments decreased during the study. These results reveal that the students' initial negative attitudes towards English, group work, and the activities became more positive over time.

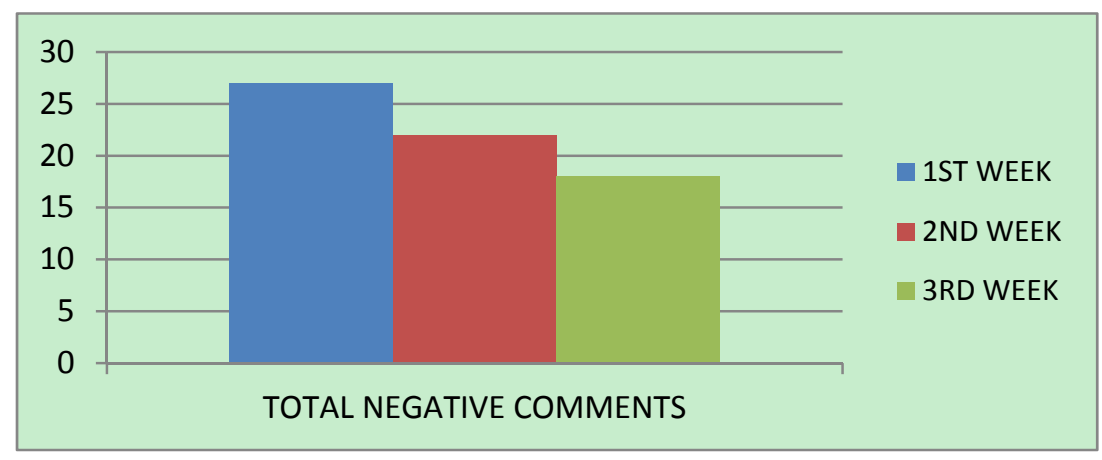

Figure 9. The range of total negative comments during the study

\subsection{The Analysis of the Interview with the Teacher}

An interview was conducted by the researcher with the teacher who implemented Kagan Structures with the experimental group. The researcher interviewed the teacher after the analysis of the lesson diaries to verify the results obtained from the lesson diaries by asking questions to the teacher. There were nine questions asked in total. The major themes, which were identified by perusing the lesson diaries, were discussed with the teacher in the interview. The teachers' reflections helped show a statistical gain in the comments in the lesson diaries, which were written by the experimental group. The researcher transcribed the interview many times in detail and identified patterns and themes related to the aim of the interview.

Firstly, the researcher asked about the students' attitudes towards English before the teacher implemented cooperative learning strategies in the classroom. The teacher stated that most of the students liked English. She also pointed out that a few students generally have negative attitudes towards English lessons. According to the teacher, the attitudes of the students depend on whether or not they like the activities used in that lesson. She noted:

"Most of the students have positive attitudes towards English lessons. Nevertheless, there are still some students that keep saying that they do not like English ever. Some of my lessons may be enjoyable for them; some of them may be boring. When they enjoy the lesson, they generally state that they love English. However, I sometimes observe displeasure on their face because they do not enjoy the activities. What I mean is that their attitudes change from time to time".

Secondly, the researcher asked how the students' attitudes towards English changed during the study. The teacher explained that she was more active in the classroom before the study and she noticed some bored students. She also pointed out that the students might be interested in different things because they were bored. She said: 
"To be honest, I was at the centre of the lesson before the study. I was presenting everything. I was helping them when they had difficulties. The students were just completing worksheets and checking the answers as a whole class. I can understand now why some of them were bored. They were not active enough. They were asking what time they had for break time or they were interested in different things such as drawing, writing something or reading a book under their desks".

While talking about the period during the treatment, the teacher noted that she faced a little conflict in the first week of the treatment and still observed some displeased students in the classroom. She also stated that the students started to express their pleasure over the new lessons. She went on to say:

"In the first week of the study, they could not understand what they were going to do. To tell the truth, there was a little bit of conflict in the classroom. I still heard some voices saying "I do not like this, I do not want to do that, etc". However, during the other weeks, I saw the pleasure on their faces. Except for one or two students, I did not any bored students. Even in other lesson in which I did not implement cooperative learning strategies they were asking whether they would work in groups or not".

Another one of the questions focused on how the students used to feel while working in groups before the treatment. The teacher explained that the students did not divide the tasks equally. Low-achieving students lacked of self-confidence during the group work. She stated:

"Before I implemented Kagan structures in the classroom, the students worked in groups. To be honest, I learnt the difference between group work and cooperative learning while implementing cooperative learning strategies. While working in the groups, there were not any criteria to take into consideration. They were just working in the groups. In fact, high-achievers were taking more responsibility during the group work. They were contributing academically to the groups. Low-achievers were contributing by writing or drawing. They were not so active in the learning process. They preferred standing in the background to contributing. For example, they were choosing the group leaders among the high-achievers because those kinds of students represented their groups better than others".

The researcher also asked how the students felt while working in groups and whether or not they had fun. She mentioned that they started to have fun in groups after the first week. They particularly enjoyed the teamwork and sense of camaraderie. The teacher stated:

"In the first week, there were some students who grumbled about working in groups. They had participated in just a few group works until Kagan structures were implemented. There were some complaints, which I heard from the students: They did not want to sit on others' chairs. They did not want to use their friends' desks. They did not to share their materials with their group members. However, the frequency of the complaints started to decrease over time. They got excited to work in groups. They liked answering the questions together. They internalized teamwork psychology. I believe this psychology promoted their motivation. They were sure that their groups were going to respond correctly to the question because they decided what they would say in advance".

The researcher also asked about the difficulties the students had during the activities, and the attitudes of the students towards those difficulties. The teacher specified that some of the students had some difficulties while completing certain activities, although most of them did not have any difficulties. She mentioned:

"Regarding my observation in the classroom, most of the students did not have difficulty while completing the activities. In my opinion, Kagan structures were suitable for this level. The instructions given through the activity recalled the games, which we used in the classroom from time to time. Although the activities were easy for most of them, I also observed some students who experienced difficulties. The students who were not good at English had some difficulties during the structure 'Round Table'. They were tasked with a spaghetti recipe for a cooking programme as a group. It seemed difficult for those students. The best part of the activity was that all the group members checked each other's sentences. During this stage of the activity, I observed some students who were extremely polite while correcting their group members ' mistakes. That made me really happy".

For the next question, the researcher asked whether the students liked their group members so the teacher could learn about their attitudes towards the other members of their groups. The teacher indicated that because of their age groups, they had complaints about their group members. She also stated that some of them preferred working with their best friends. The teacher pointed out:

"Forming the groups for the structures was the most tiring part of this study for me. According to the requirements of this study, I had to arrange to cooperative learning groups according to their gender, abilities, and achievement level on English. As you might guess, it is not easy to satisfy the students in some ways. They are sensitive about friendship at that age. They usually want to do everything with their best friends. During the study, some of the 
students were satisfied with their group members but some of them kept complaining about the members in their groups. One of the solutions for this problem was to change the groups before each session every week. Until the end of the study, one student had a chance to work in five different groups. Changing the groups decreased the displeasure of the students".

As a seventh question, the teacher asked about which activities the students liked most. The teacher stated:

"As far as I could see during the study, they liked most of the activities. To be honest, I enjoyed the lessons as a teacher. I had fun while teaching. I have been teaching these kids for two years. They love playing games, making crafts and singing songs. They thought that they were playing games while I was implementing Kagan structures. I saw the pleasure on their faces. If you asked me which activity they liked most, I would say 'Showdown' and 'Fan-N-Pick'structures. During the implementation of these structures, I saw that they were highly motivated'.

As the next question, the researcher asked about the changes on students' attitudes towards group work during the study. The teacher explained that whereas the students needed time to adapt in the first week of the study, they felt more relaxed the following weeks. She also stated that low-achievers benefited greatly from the study. The teacher mentioned:

"The course books which I use for my students include many group work and pair work activities. To tell you the truth, I do not prefer using group works because those kinds of activities take lots of time. As you know, I have to follow a curriculum during the year. I have to teach most of the subjects in the curriculum. What I am trying to say is that I have not offered such a kind of classroom atmosphere to them until the implementation of this study. Thus, it was normal for them to have negative attitudes towards group work. At the beginning, they could not adapt to the group work activities. In the previous group work, high-achievers used to take on the responsibility of the group, while preferred observing and taking on smaller responsibilities such as writing and procuring necessary materials. They tried to do same thing in the first week activity. Low-achievers preferred standing back. When I explained the steps of the structures, they started to understand what they were expected to do. I observed that the students who were not good at English started to feel more relaxed because they had other friends to help them whenever they needed. In short, they loved being a team. They loved doing something together, making decisions together, and answering questions together".

Lastly, the researcher asked about the students' performance during the study and the teacher's general opinions about the study. She stated that she loved teaching Kagan structures too and that these structures helped her motivate the students during the study. She expressed:

"The first thing I really want to say is that I loved teaching using cooperative learning strategies. I knew a little bit about cooperative learning before you told me about it. Nevertheless, I learnt the details about this approach while implementing Kagan structures. During the study, I did some research about these structures, cooperative learning, basic principles of this approach, etc. I went over information I already knew; sometimes learnt something new. The most important thing was that I saw the pleasure of the students. As you know, it is very difficult to motivate young learners during lessons. At that point, Kagan structures helped me by attracting the students with their game-like instructions".

Regarding the interview with the teacher, it can be inferred that there is a correlation between the data obtained from the lesson diaries and the data obtained from the interview with the teacher.

\section{Discussion}

As mentioned in Chapter II, there are many studies, which were conducted to investigate the effects of cooperative learning on different aspects of language skills. The researcher presented these studies and their aims while reviewing the literature. In the discussion section, the findings of these studies will be discussed in direct comparison with this study.

One of the studies in this area was conducted by Bayat (2004); it investigated the effects of cooperative learning on students' attitudes towards English reading courses and cooperative learning. This study also aimed to discover possible differences in the attitudes of male and female students and high-achievement and low-achievement students towards the reading course and cooperative learning activities. The data was collected through pre and post questionnaires and interviews with the students and the teacher. It was found out that there was not a significant difference between the statistical results for the experimental group and the control group. However, the analysis of the interviews with the students indicated that they had positive attitudes towards reading courses in which cooperative learning strategies were implemented. It was also found out that cooperative learning experience helped the students improve their management, social, and academic skills. Unlike the study conducted by Bayat (2004), this study investigated the effects of cooperative learning strategies on the students' academic skills rather than social skills. This study did not focus on the 
difference between the attitudes of male and female students or high-achievers and low-achievers. This study aimed to learn the students' attitudes without regard to the gender, age, or ability.

In this area, another study conducted by Ercan (2009) aimed to determine whether Cooperative Learning or the traditional way of teaching vocabulary was more effective in improving preparatory class young adult learners' vocabulary recognition. Pre and post tests were administered to the experimental group and the control group to examine whether there was a difference between the two groups of students- a group taught vocabulary through cooperative learning and another group taught vocabulary through traditional teacher-based way. At the end of the study, the results revealed that both the experimental group and the control group performed better after the study. However, the experimental group scores were significantly better on the post-test. Unlike the study carried out by Ercan (2009), this study also aimed to investigate the effects of cooperative learning strategies in improving both vocabulary recognition and vocabulary production skill of the students. The results of both studies were similar. The results of this study also indicated that the experimental group performed better on the post-test than the control group.

In another similar study carried out by Çokparlamış (2010). The researcher aimed to find the probable effects of cooperative learning in reaching the fifth grade syllabus objective and student perception of classes, in which cooperative learning methods were used. The results revealed that there was a significant difference between the control group and the experimental group according to the results of the pre and post tests. It was clear that the experimental group developed their skills more rapidly during the study. It was also found out through the analysis of the diaries that the students liked cooperative learning. In this study, it was also found out that the experimental group had a higher score than the control group. The results also revealed that most of the students liked cooperative learning strategies. The results show that most of the students had fewer positive comments in the first weeks of the treatment than the middle weeks and the last week of the study. It can be clearly understood that the students in the experimental group had much more positive attitudes towards group work after they got used to working in the groups during the following weeks. Furthermore, a few of the students' attitudes towards the lesson were negative. After the first week, the frequency of those negative comments decreased. Nevertheless, it was reported that there were still negative comments in the last week of the study. Unlike the study conducted by Çokparlamış (2010), this study aimed to learn the teacher's opinions about the students' attitudes toward group work to verify the results obtained from the diaries.

Lastly, this study also revealed some findings contrary to the researcher's expectations. While analyzing the lesson diaries of the students in the experimental group, the researcher expected to find more positive comments in their diaries. The small increase in the number of positive comments during the study was not satisfactory for the researcher. The researcher expected a more observable increase before the study. The researcher also did not observe a satisfying decrease in the number of the students who had negative attitudes towards English.

\section{Conclusion}

While English is becoming a global language and the government of Turkey is emphasising the importance of English by developing a new curriculum, we can see that the significance of English is recognized all over the country. The new curriculums developed by the government or private educational institutions are mostly based on communicative approaches and student interaction. Since the learner-centred learning was emphasized in the new curriculum, traditional strategies based on teacher-centred learning have started to lose their significance. Thus, teachers have been looking for new strategies to implement the new curriculum in their classroom. As an alternative strategy for the requirements of the current English curriculum, cooperative learning is selected by the researcher.

This study was an effort to discover the efficacy of cooperative learning strategies on vocabulary teaching and the students' attitudes towards the sessions in which those strategies were implemented. Consequently, it has been found that cooperative learning strategies have a positive effect on students' vocabulary skills. It has been also noted that the students' attitudes towards English, group work and the activities (Kagan structures) have changed for the better during the study. Regarding the results of the study, it can be claimed that using cooperative learning strategies while teaching vocabulary helps the students learn and retain the vocabulary words they learn. It also creates a positive learning environment for the students.

\section{Acknowledgements}

We owe so much to all our family members for their unconditional love and continuous encouragement. Their endless patience throughout the entire process motivated us to complete this study.

\section{References}

Akar, N. (2010). Teaching Vocabulary Bridging the Gap between Theory and Practice. Ankara: EDM.

Bayat, Ö. (2004). The Effects of Cooperative Learning Activities on Student Attitutes Toward Reading Courses and Cooperative Learning. Ankara: Bilkent University. 
Büyüköztürk, Ş. (2012). Sosyal bilimler için veri analizi el kitabı: İstatistik, araştırma deseni, SPSS uygulamaları ve yorum. Türkiye: Pegem.

Cameron, L. (2005). Teaching Languages to Young Learners. Cambridge: Cambridge University Press.

Davoudi, A. H., \& Mahinpo, B. (2012). Kagan Cooperative Learning Model: The Bridge to Foreign Language Learning in the Third Millennium. Theory and Practice in Language Studies, $2($ 6), 1134-1140. http://dx.doi.org/10.4304/tpls.2.6.1134-1140

Ercan, E. (2009). Teaching Vocabulary through Cooperative Learning. Konya.

Ghorbani, M. R. (2012). Cooperative Learning Boosts EFL Students' Grammar Achievement. Theory and Practice in Language Studies, 1465-1471. http://dx.doi.org/ 10.4304/tpls.2.7.1465-1471

Johnson, D., \& Johnson, R. T. (1999). Learning together and alone: Cooperative, competitive, and individualistic learnin (5th ed.). Boston: Allyn and Bacon.

Kagan, S. (1985). Kagan Cooperative Learning. San Clemente, California: Kagan Publishing.

Kagan, S. (1999). Cooperative Learning: Seventeen Pros and Seventeen Cons plus Ten Tips for Success. Kagan Online Magazine. http://www.kaganonline.com/

Kagan, S. (2003). A Brief History of Kagan Structures. Kagan Online Magazine.

Kagan, S. (2003). Kagan Structures: Research and Rationale in a Nutshell. Kagan Online Magazine. Retrieved from http://www.kaganonline.com/

Kagan, S. (2011). Kagan Structures and Learning Together - What is the Difference? Kagan Online. Retrieved from http://www.kaganonline.com/

Kessler, C. (1992). Cooperative Language Learning A Teacher's Resource. United States of America: Prentice Hall Regents, Prentice- Hall, Inc.

Liang, X., Mohan, B. A., \& Early, M. (1998). Issues of Cooperative Learning in ESL Classes: A Literature Review. Tesl Canada Journal, 13-23. http://teslcanadajournal.ca/index

Nunan, D. (1992). Introduction In D.Nunan (Ed.) Collaborative language learning and teaching. Cambridge: Cambridge University Press. http://dx.doi.org/10.1515/9783110850512.1

Philips, S., \& Shipton, P. (2014). World Explorers 2 Class Book. Oxford: Oxford University Press.

Richards, J. C., \& Rodgers, T. S. (2001). Approaches and Methods in Language Teaching. Cambridge: Cambridge University Press. http://dx.doi.org/10.1017/CBO9780511667305

Scrivener, J. (1998). Learning Teaching. Oxford: Macmillan Heinemann.

Sharon, S. (1990). Cooperative learning: Theory and research. Westport: CN: Praeger.

Slavin, R. E. (1995). Cooperative learning theory, research and practice. Massachusetts: Simon\&Schuster, Inc.

Swain, M. (2001). Examining dialogue: Another approach to content specification and to validating inferences drawn from test scores. Language Testing, 275-302. http://dx.doi.org/ 10.1177/026553220101800302

Swain, M., \& Lapkin, S. (2002). Talking it through: Two French immersion learners' response to reformulation. International Journal of Educational Research, 285-304. http://dx.doi.org/ 10.1016/S0883-0355(03)00006-5

Tekeli, S. (2013). The Effects of Cooperative Learning on Students' writing Performance. Çağ University Institute of Social Sciences English Language Department. MERSIN.

Van Lier, L. (1996). Interaction in the language classroom. Essex: Longman Group.

Vygotsky, L. (1962). Thought and Language. New York: Wiley. http://dx.doi.org/10.1037/11193-000

Vygotsky, L. S. (1978). Mind in Society:The Development of Higher Psychological Processes. Cambridge: MA:Harvard University Press.

Zarei, A. A., \& Gilani, M. S. (2013). L2 Vocabulary Learning Through Collaborative Techniques. International Journal of Language Learning and Applied Linguistics World, 71- - 84. Retrieved from www.ijllalw.org 